\title{
Academic Video in the Portuguese High Education Network: the EDUCast@fccn project
}

\author{
Samuel Martins ${ }^{1}$, Hugo Ribeiro ${ }^{2}$, Rui Ribeiro ${ }^{3}$, Nelson Dias $^{4}$ \\ ${ }^{1}$ University of Porto, Praça Gomes Teixeira, 4099-002, Porto, Portugal, sfm@reit.up.pt \\ ${ }^{2}$ University of Porto, Praça Gomes Teixeira, 4099-002, Porto, Portugal, hribeiro@reit.up.pt \\ ${ }^{3} \mathrm{FCCN}, \mathrm{Av}$. do Brasil n. ${ }^{\circ} 101,1700-066$ Lisboa , Portugal, rui.ribeiro@fccn.pt \\ ${ }^{4}$ FCCN, Av. do Brasil n. ${ }^{\circ} 101,1700-066$ Lisboa , Portugal, nelson.dias@fccn.pt \\ Keywords \\ Video, education, e-learning, b-learning.
}

\section{ABSTRACT}

Since 2010 it was developed an innovative partnership initiated by the Portuguese Foundation for National Scientific Computing (FCCN), by SWITCH (the institution that manages the Swiss Network Technology Research and Education) and the University of Porto (U.Porto). These three European institutions have developed a work of exploration and discussion under the auspices of TERENA (Trans-European Research and Education Networking) during the various forums for collaboration, innovation and knowledge sharing that this institution regularly promotes. Thus, was born in Portugal the project Educast@fccn that can be considered the simplest national service to manage educational video from recording to the distribution process. This service is based on a technology platform for production, editing and video distribution that allows full autonomy to the user in all the process. In addition to the innovative technology, this service provides to all High Education Institutions (HEl's), in Portugal, the integration into a professional structure that supports the production of audiovisual content for e-learning and blended learning in each institution and a great possibility of scaling the production on each one of the institutions. The specific logistics of each HEI in Portugal and the specific teaching of each academic community are some of the major challenges faced by technical staff, administrative staff and educational support staff of these institutions when trying to find an appropriate solution for the provision of audiovisual content. Therefore this professional network structure also ensures a high level of service support, and consequently, a great confidence to the teachers and other audiovisual content producers in the various academic communities in Portugal. But this project also allowed, since its inception, to consolidate a national community of experts in content development for e-learning and blended learning, especially the audiovisual components. The $U$. Porto also positioned itself as a pivotal entity in this privileged national network of experts on audiovisual content on education through the training of 80 employees spread across $37 \mathrm{HEl}$ 's in Portugal during the last 2 years. In addition the U.Porto released a set of complementary initiatives ranging from training, workshop sessions and distance learning courses about this technology and this service. This was an ambitious step of this big national project that allowed to build a set of technical teams specialized in the production of educational content and that directly support the academic communities of their own institutions. Currently this project is confirming the high expectations of those involved and is creating even bigger expectations to the future. About $37 \mathrm{HEl}$ 's joined the EDUCast@fccn project with 2306 users and 5882 videos produced and integrated in 748 channels of project platform. These significant quantitative results are the visible part of a set of technological and logistic conditions to start a strong manifestation of significant qualitative results regarding the educational impact of this project in the daily activities of teachers. Aspects such as the better management of lectures that are traditionally less appealing, the attractiveness of the educational contents created through video, the improved productivity of teachers through the recording of audiovisual content, the release and allocation of teaching time for productive activities and to the interactive direct support to the student or even the increase of the students' interest in certain content that traditionally would not be so appealing, are just a few issues that constitute these qualitative aspects. 


\section{STATEMENT AND BACKGROUNG INFORMATION}

Over the years the recordings of lectures and the development of an academic video solution in the Portuguese Higher Education network constituted a major challenge to all the stakeholders. The specific logistics of each HEI and the specific teaching of their academic communities are some of the major challenges faced by technical staff, administrative staff and educational support staff of these institutions when trying to find a suitable solution for providing this kind of audiovisual content. The involvement of the technology services and appropriate educational services, the articulation of policies and procedures and correct focus on the needs of real users of these technologies are, therefore, crucial attitudes to the implementation of any project in this area. Conscious of this reality, it was started in 2010, an innovative partnership initiated by the Portuguese Foundation for National Scientific Computing - $\mathrm{FCCN}^{1}$ (Portuguese manager of the National Research and Education Technology technological network), by SWITCH ${ }^{2}$ (Swiss manager of the National Research and Education Technology technological network) and the U.Porto ${ }^{3}$, the largest university in Portugal. Incorporating a true European spirit of creating synergies between European institutions, in 2010 began an ambitious project of robust technology transfer and adaptation for the Portuguese academic and teaching environment in Portugal, unprecedented in this country and Europe. This European innovative partnership resulted in a labor intensive exploration of ideas, of knowledge and experience on technical issues and legal aspects of production, management and distribution of audiovisual services federated at national level and even a pan-European level. (Zbinden 2010). These three European institutions have developed this exploration work under the auspices of TERENA ${ }^{4}$ (Trans-European Research and Education Networking) during the various forums for collaboration, for innovation and knowledge sharing that this institution regularly promotes. The discussion of workflow processes, the different platforms and services management of audiovisual content and the ability to federate media repositories are just a few examples of topics discussed in this forum (including the specific forum sponsored by the TF-Media (Vena 2009), a working group specific from TERENA and that allowed the promotion of voluntary meetings that culminated in this innovative tripartite partnership.(Ribeiro 2011). Thus was born in Portugal, in 2011, the Educast@fccn ${ }^{5}$ project that is defined as a national service to manage educational video from recording to the distribution process. This service is based on a technology platform for production, editing and video distribution that allows full autonomy to the user in all the process. In addition to the innovative high technology, this service provides to all HEl's in Portugal an integration into a professional structure to support the level of production of audiovisual content for e-learning and blended learning. This structure relies on the support of professionals to ensure high levels of service and, consequently, a great confidence to the teachers and other audiovisual content producers in the various academic communities in Portugal. But this project also allowed, since its inception, to consolidate a national community of experts in content development for e-learning and blended learning, especially in the audiovisual field. (Ribeiro 2011). The U. Porto, through its unit of New Technologies in Education (which manages one of the most ambitious elearning and blended learning services in Portugal) from the beginning was the strategic partner that would assist in the structuring of the pedagogical aspects and implementing the local service of the Educast@fccn at U.Porto.

The New Technologies in Education unit as a decade of experience in supporting the development of distance learning in the U.Porto and constitutes one of the most ambitious and innovative services in Portugal concerning this area. This unit currently manages more than a thousand blending learning courses from the U.Porto and leads the implementation of pure e-learning courses in this University. Furthermore, this unit implements every year a strong pedagogical and technological training of teachers in this University and supports a vast multimedia production that supports teaching and learning. Several state-of-the-art services are provided like the support to online exams, computer-

\footnotetext{
1 www.fccn.pt

2 www.switch.ch/

${ }^{3}$ www.up.pt

${ }^{4}$ www.terena.org

${ }^{5}$ http://educast.fccn.pt
} 
based assessments and e-portfolios. The unit team actively participates in several international ICT projects and continuously publishes papers and articles in national and international conferences. This vast experience has positioned the New Technologies in Education unit as a fundamental player to develop the EDUCast@fccn project from the pedagogical and human resources point of view. Beside the implementation of this project in their own academic community (with about 2.500 teachers and 30.000 students in 14 colleges distributed in three campus), the U. Porto also positioned itself as a pivotal entity in this privileged national network of specialists in audiovisual content on education through the training of about 80 employees spread over $37 \mathrm{HEl}$ 's in Portugal. In addition the U.Porto released a set of complementary initiatives ranging from training, workshop sessions and distance learning courses about this technology and this service. Most of these iniciatives concerned to the use of technology in education and the pedagogical aproaches to that use. Several public sessions and pratical workshops were moderated by the New Technologies in Education team, like the University of Minho workshop represented in Figure 1.

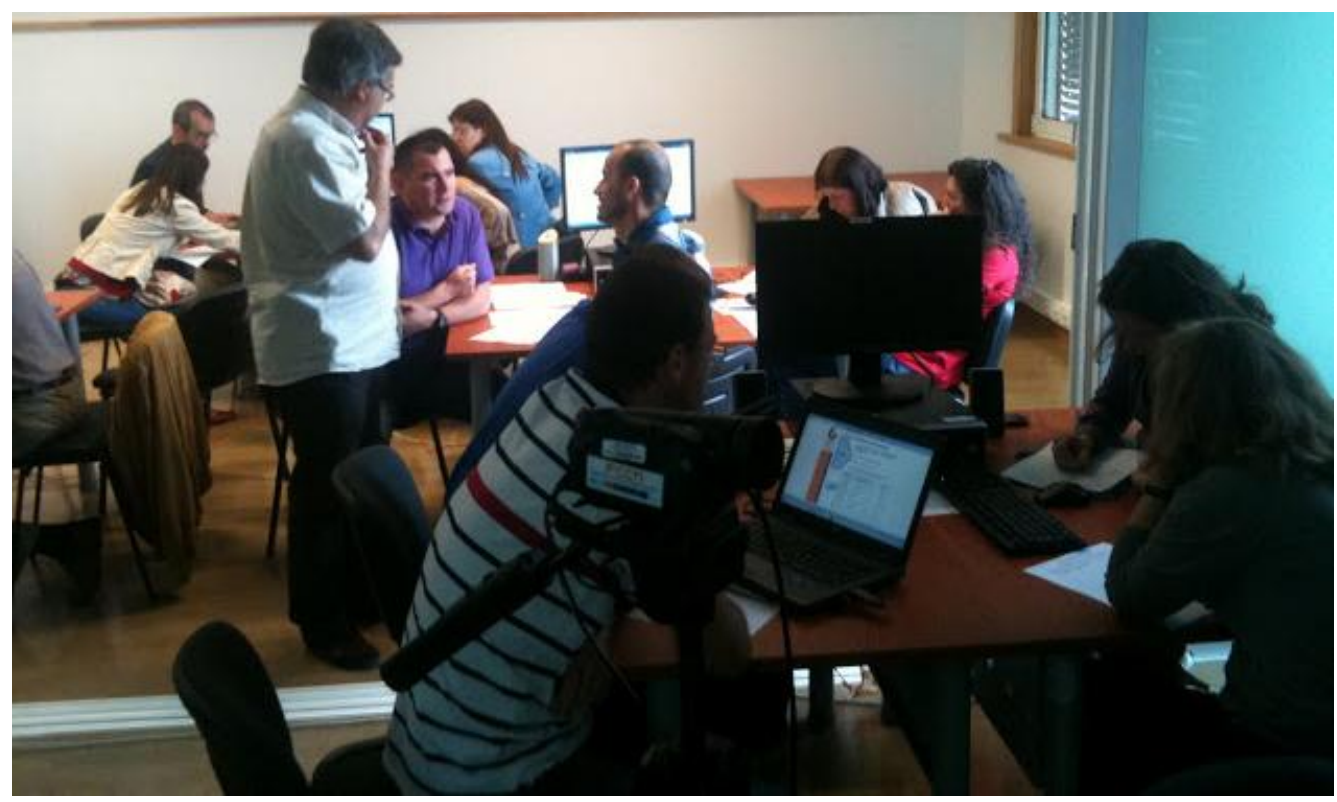

Figure 1. Teachers workshop about the use of the EDUCast@fccn service in the University of Minho.

Plus this work of dissemination, the New Technologies in Education team setup in 2012 a distance learning course entitled "Educational Videos Production - EDUCast" which offered an even larger opportunity of training to all the academic community. This blending learning course was a great success with more editions in planning by the U.Porto New Technologies in Education team. All this work allowed to train not only a network of technical teams specialized in the production of educational content but also the main final users of this technology: the teachers and pedagogical content producers. The fact is that we see significant quantitative results that are the visible part of this project. About $37 \mathrm{HEl}$ 's joined the EDUCast@fccn project with 2306 users and 5882 videos produced and integrated in 748 channels of project platform. From the quantitative point of view we can verify an increasing growth in the video production over the years, which may indicate that these stakeholders are in position to show significant qualitative results regarding the educational impact of this project in the daily activities of them. We can say that is created a technological and logistic set of conditions do develop a strong pedagogical approach that can have impact on the teacher's daily activities and students achievements. Keeping with the true European spirit of technological synergies, the European spirit of humanities synergies, the European spirit of networking and collaborative technologies designed to maximize people's work and, above all, culminate in positive practical results for the academic communities, the Educast@fccn project can be one of the best European examples of those ideals. 


\subsection{The innovations of the project}

The national partnership between the U.Porto and FCCN is considered an innovative model with regard to collaboration with technical teams from different institutions. Without addition of human resources for the purpose of this project it was possible to build a structure of national training and ongoing technical support also nationwide with the existing human resources at the $\mathrm{U}$. Porto (via the unit of New Technologies in Education) and FCCN (through the Advanced Services and Audiovisual staff). But we must regard also the spirit of an European partnership at national and at local level with a tripartite European partnership (SWITCH-FCCN-U.Porto) that allowed the creation of an ambitious project which brings a set of capital gains not only for the institutions involved but also for the entire academic community in Portugal ${ }^{6}$. The central support structure located in two different cities of the country (Lisbon and Porto) separated by 300 kilometers away, can respond in a professional manner to all requests in the country. This structure has a good flexibility and agility in responding to technical and pedagogical advice to all the local teams of all HEl's in Portugal. It is in this structure that also turns the entire national community of educational video producers and audiovisual content for e-learning and blended learning in all the academic community in Portugal. This innovative approach allows to Portugal to enhance knowledge sharing and dissemination of good practices in the creation of oriented-teaching audiovisual content. These features allow you to add a confidence factor very important to this community and create conditions for a constant evolution of technologies, of practices, of procedures and the correct spread throughout the academic community in the country. This structure permits to achieve the highest points of quality in the state of the art of audiovisual content production all over the country academic community. The technological component of the project is also a real innovation and it is explained in more detail in section 1.3 of this paper. The characteristics of the platform associated with the Educast@fccn project concern the vast majority of educational content with potential for audiovisual recording. The synchronization characteristic and the characteristics of simplicity of the platform (with the availability of basic functions of recording, editing and delivery) will help achieve a potential community of content producers with less training and predisposition to the ICT in general and audiovisual technologies in particular. Finally, the scope of this project (fundamental aspect when we are dealing with audiovisual equipment and all its associated logistics) using the local structure located in each of the HEl's is one of the most innovative features of this project. Working in a logical structured and hierarchical way (teacher user > local technical team > national technical team > FCCN) the operation of this network ensures a high level of quality and service support and enhance the quality of content. In the Portuguese academic environment, that it is traditionally rigid on the drive of the articulation of internal and external partnerships and in a time when the optimization of resources is on the horizon of all institutions, the project Educast@fccn constitutes a true innovation in its model of operation and with features that allow a permanent innovation for everyone involved.

\subsection{Pedagogical and educational foundations}

In a time when teachers are required to put themselves as teachers and learners, in the expectation that, through the interaction established in the communication with students, the learning process take place for both of them, the video is positioned as a resource to boost the pedagogical task. Several authors stress that the video is a visual communication tool that facilitates the assimilation of information content (mobilizing more than one human sense to the understanding of the videographic narrative) and has the power to mess with the emotional, with the fantasies, with the desires and feelings, facilitating the understanding of the didactic message and appealing to the involvement of the student in the context. (Lisbôa, Junior et al. 2009). We all know that video cannot be considered only as a resource to support the lessons, because above all it is a mean of communication. And with this aspect in mind, this project Educast@fccn can be part of a strategy for teaching and learning that give students a variety of activities, whether to analyze the different styles of language, either to analyze the positive and negative aspects of various messages presented or for the production of personal research or even to a self-assessment of his journey in a specific discipline or course. There are countless ways to use video in learning. It is for the teacher to choose

\footnotetext{
${ }^{6}$ See more documentation about this project in the dedicated University of Porto webpage;
} 
the best way to include this feature in the classes. The way chose can encourage students to develop skills and abilities needed for the basic skills so that the information obtained through this feature may apply to other contexts of their life and thus ensuring a meaningful and situated learning. The administrative and technical structures of higher education institutions in Portugal must be prepared to respond to such demands. With the Educast@fccn project this flexibility is achieved through the technical solution of the platform itself, but primarily through the community and dedicated technical experts who can assist and advise directly the teaching community. The challenge for lecturers is now how to create a learning context in order to maintain or increase the number of students motivated, with effective learning results, in a new scenario where the traditional classroom lectures are substantially reduced. To do this, the approach to lecturer/student's interaction must be reconsidered. (Adão 2007). It is necessary to change the content's format, the mean to distribute the contents, the learning activities purposed, the communication policy and the assessment criteria. The Educast@fccn project stands as a technological and logistical solution suited to this new context. In a student oriented learning process, where the student has the responsibility to plan and manage his own learning path, the lecturer still have the essential role of creating a suitable learning context. After a period of experimental projects, e-learning is now starting to grow and being disseminated throughout universities. But most of the contents are not adjusted to the new methodologies and are still oriented for formal/classroom education. To what concern lecturers, there is some natural resistance to even try such a different approach to their (conventional) activity. Some of them are suspicious about the real value of video in learning contexts and think it does not worth the time they would spend. Others do not feel comfortable with what seems to be a very technological demanding approach. They are all right, at least from their point of view. It is impossible to force a lecturer to make a good video content if he/she does not believe in it, or has any kind of preconceptions about technology affairs. To make a good video content a lecturer need to develop some technical and non-technical skills. It is desirable to understand and know how to use the technology involved and it is necessary some imagination and lecturing experience to put together different media resources towards a common learning objective, just like exploring alternative ways to the same place. All it needs is some training and, of course, the incentive to change. (Adão 2007). The lack of training and support are two of the major problems identified in the HEl's, leading to unmotivation among teachers and the video is viewed primarily as a means of motivation and awareness of content.(Silva 2010). With about $37 \mathrm{HEl}$ 's adhering so far to the Educast@fccn project and 5882 videos produced with a total of 2306 users. With the constitution and evolution of this significant critical mass of audiovisual content producers is almost inevitable that in a near future arises a qualitative improvement of the content in order to achieve different educational objectives. That's the future evaluation work that the Educast@fccn team will focus from now on. It will also be very important, therefore, that good practices and case-studies be widespread in the future. From the thematic point of view we can see already some very significant data of the pedagogic potential of this technology and the Educast@fccn service. By the first quarter of 2013 about 33\% of the production was made in the Education field whereas the Technology subjects represented $11 \%$ of the audiovisual production that used the Educast@fccn service. The Technology field that is supposedly more predisposed to using this type of service is the fourth tematic area with most produced videos after Law (17\%) and Health $(16 \%)$ in the EDUCast project. The remaining subjects (Art and Culture, Humanities, Social Sciences, Natural Sciences and Mathematics) divide among themselves the remaining production rates.

These values are starting to show the potential for thematic scope of this service, achieving subject areas which are not traditionally prone to the use such technologies in developing their contents. It is viewed that in a near future the pedagogical and technical teams are able to focus on educational support of this work. The technological infrastructure provided by the Educast@fccn project allows the creation of the conditions for focusing the work support in this qualitative aspect. In fact, behind these quantitative results its starting to appear some qualitative results regarding the educational impact of this project in the daily activities of teachers. (Soares 2011). There are not yet significant results properly measured and scrutinized for these qualitative aspects. The information obtained relate only to what withdraws from informal conversations between technical teams and teachers interested in using this type of technology. Aspects such as better management of lectures that are less appealing, the attractiveness of the educational contents created, the improved productivity of teachers through the recording of audiovisual content, the release and allocation of teaching time for productive activities and interactive direct support to the students or even 
increase the student's interest in certain content that traditionally would not be so appealing, are just a few aspects of these potential qualitative results.(Soares 2011).

\subsection{Value added technology}

One of the most important gains of this project is to ensure the technical requirements of all technical phases of the normal video production process, including the video editing and the final availability. Thus, early in the project it was ceded to six HEl's an audiovisual kit that will help to spur the production phase of this project. These six kits consist of a set of basic equipment (laptop, camcorder, lapel microphone and some cables) that allow the user to use and produce audiovisual content across the Educast@fccn platform in the best possible way. The portability of the equipment is a great asset, allowing a very significant flexibility. In addition, the concept of this kit is an example to all other HEl's on how to create forms of provision of audiovisual equipment in their own institutions. The classroom is the default location for this service and the concept of audiovisual. The equipment available in this kit allow the optimal integration in the classroom allowing also the smallest possible physical occupation in the normal course of the lesson. For the recording process, the interface used for this purpose is characterized by simplicity. From this interface you can configure the video image (which you can opt for an external camera or the internal camera of the computer), you can set the image data of the classroom that will be recorded simultaneously (immediately creating a synchronization between video image and the image data) and you can select the microphone of your choice to make the recording. The possibility of immediate data synchronization with the video image is a major asset to this platform. It is a technical concept that goes forward with one of the greatest needs of academic communities and also with the type of content that it's taught in the classroom (the teacher presenting data in a classroom). Another highly productive characteristic of this platform is the editing tool. The video editing tool is exclusively online and is only available after uploading the video. This feature provides great flexibility and autonomy to the editing process, if necessary. The lecturer, after performing the recording of your class and implementing its upload to the Educast@fccn server, can edit their video from their home or other location with Internet access. In addition to the full autonomy and flexibility of this process, the editing features of this platform will meet the needs of a large number of teachers. You can create several video clips from the main video recorded, you can create chapters and have captions, you can assign a set of basic metadata identification of the video and you can assign a set of branding features on the video. The final stage of publishing the videos is one more asset to this Educast@fccn platform. There are several formats available for the videos that are created through this service and, in particular, through this platform. There are three types of video formats available (the Flash format, the QuickTime format and the iPod suitable format), there are also different ways of integrating these videos provided by this platform. ${ }^{7}$ This integration can be an individual integration of the video or by integrating multiple channels containing several videos. One of the added values of this Educast@fccn platform is its conditional access to the NREN community (RCTS), the Portuguese community of Education, Science and Technology through the AAI Federated Authentication service. This conditional access to this community allows to focus the use of this service and to focus the content produced at the RCTS. From the technical standpoint view, the platform has three levels of access to the backoffice (the access producer level, the local administrator access level and the national administrator access level). This structure ensures a technical quality service with different levels of intervention and monitoring. The access producer level for the normal user, the local administrator access level to the dedicated technical team of a specific HEl that provides the local support and the administrator access level to the dedicated national team (formed by the FCCN and U.Porto) who oversees the project. With this structure all the steps of creating an audiovisual content are provided by a process of ongoing support to all levels (the teacher user > the local technical team of the HEI > the national technical team formed by FCCN-U.Porto). This structure permits a high level of confidence among potential creators of audiovisual content (especially for the teaching staff) and forms awareness about this mechanism for ongoing support throughout all audiovisual development process. As we know, this confidence is a major factor to foster the creation of content in the academic community, and especially in the teaching community. Finally, from the video publishing viewpoint there is also the possibility of

\footnotetext{
${ }^{7}$ See the examples available in the U.Porto ICT Portal and U.Porto E-learning Portal.
} 
conditioning the publication view. Thus, it is possible to condition the display of each channel of the Educast@fccn platform with four types of display: public viewing, federated viewing, organization viewing and the private viewing. In short, the public viewing allows anyone to view the videos of the specific channel that has this permission, the federated viewing allows videos to be viewed only by institutions from the RCTS, the organization viewing conditions the visualization only to a specific $\mathrm{HEl}$ and, finally, the private viewing allows only the producer of this channel to view their videos.

\subsection{Usefulness and benefits of the innovation}

One of the main challenges for the technical and pedagogical teams of the HEl's is to make available the video technologies that encourage the construction of knowledge and, simultaneously, technologies that are easy to use by teachers. (Collin 2010). Several studies imply that video can be an effective medium to present authentic situations in order to enhance student satisfaction, empathy, and learning achievement in problem-based instruction.(So, Pow et al. 2009; Choi and Yang 2011). By using this Educast@fccn service and their associated technology it will be possible for each HEl to suit their specific type of use. Many HEl's intend to implement a proper and dedicated system of lecture recording that may provide the classes on demand. Others HEl's want to establish a different approach. Some studies show that the students who attended few lectures had more benefit from viewing online lectures than students who attended many lectures. (Wieling and Hofman 2010). This flexibility that can be found in the service and the platform associated with the Educast@fccn project allows this utility, and consequently all the benefits associated with it. From the administrative point of view this project has the potentiality to improve the technical agility of responding to the teacher's requests on the audiovisual content production related to the pedagogical content. From the pedagogical point of view this project has the huge potential of enhance aspects such as the better management of lectures that are traditionally less appealing, the attractiveness of the educational contents created through video, the improved productivity of teachers through the recording of audiovisual content. Other aspects, that are already beginning to be perceived from the teaching staff ${ }^{8}$, are the release and allocation of teaching time for productive activities and to the interactive direct support to the student or even the increase of the students interest in certain content that traditionally would not be so appealing, are just a few aspects that constitute these qualitative aspects. Even the editing features of the Educast@fccn platform can position itself as a powerful tool that substitutes the writing reflections based on memory to help preservice teachers analyze and reflect on their teaching like is discussed in some literature. (Miranda 2008; Rosaen, Lundeberg et al. 2010). These authors explore constructing video cases as a means to promote analysis of a particularly complex practice, learning to lead classroom discussions and even the video production as a pedagogical instrument in the teaching-learning process. A proper implementation of this Educast@fccn service allows teachers, for example, to implement even a discussion of each of the elements of the audiovisual narrative and think of them from a perspective of education. (Souza 2009). Regardless of how you use this type of technology, it is always essential the pedagogical structuring and the role of the teacher. The structuring of tasks to facilitate students' ability to collaborate and to perceive and resolve the conflicts, contradictions, and tensions that arise during the course of the activities is important. (Macy 2011). The scope of this Educast@fccn project (fundamental aspect when we are dealing with audiovisual equipment and all its associated logistics) using the local structure located in each of the HEl's is one of the most useful features of this project. Working in a logical structured and hierarchical way (teacher user > local technical team > national technical team > FCCN) the operation of this network ensures a high level of quality and service support and enhance the quality of content. In the Portuguese academic environment, that it is traditionally rigid on the drive of the articulation of internal and external partnerships and in a time when the optimization of resources is on the horizon of all institutions, the Educast@fccn project constitutes a true innovation in its model of operation and with features that allow a permanent innovation for everyone involved.

\footnotetext{
${ }^{8}$ See the U.Porto E-learning Workshop and E-learning Excellence Award case studies.
} 


\section{CONCLUSIONS}

The results of the project implementation in Portugal, by the first quarter of 2013, confirm the high expectations of those involved and continue to augur a promising future for the expansion of this project. About $37 \mathrm{HEl}$ 's joined the project Educast@fccn so far with 2306 users. About 5882 videos were produced and integrated in 748 channels of the EDUCast@fccn platform. The Educast@fccn project is based on a technology platform for production, editing and video distribution that allows full autonomy to the user in all the process. One of the most important assets is its human based process that adds to the innovative technology a service provided to all HEl's in Portugal with the integration into a professional structure that supports the production of audiovisual content for e-learning and blended learning in each of these institutions. The sense of community and network collaboration in this field was never so cohesive and numerous in Portugal. With these quantitative results it is created a set of technological and logistic conditions in Portugal to start a strong manifestation of significant qualitative results regarding the educational impact of this project in the daily activities of teachers. Aspects such as the better management of lectures that are traditionally less appealing, the attractiveness of the educational contents created through video, the improved productivity of teachers through the recording of audiovisual content, the release and allocation of teaching time for productive activities and to the interactive direct support to the student or even the increase of the students' interest in certain content that traditionally would not be so appealing, are just a few aspects that constitute these qualitative aspects. Keeping with the true European spirit of technological synergies, the European spirit of humanities synergies, the European spirit of networking and collaborative technologies designed to maximize people's work and, above all, culminate in positive practical results for the academic communities, the Educast@fccn project can be one of the best European examples of those ideals.

\section{REFERENCES}

Adão, C. M. C. d. J. (2007). Tecnologias de streaming em contextos de aprendizagem. Escola de Engenharia. BUM - Dissertações de Mestrado, Universidade do Minho. Master.

Choi, H. J. and M. Yang (2011). "The effect of problem-based video instruction on student satisfaction, empathy, and learning achievement in the Korean teacher education context." $\underline{\text { Higher }}$ Education 62(5): 551-561.

Collin, J. (2010). Using hyperlinked video to increase motivation and learning: The HyperCaster approach. National Library of Sweden, Stockholm University.

Dias, Nelson Mendes Schäller (2012). " A utilização da plataforma Educast@fccn, como ferramenta de gravação de aulas no ambiente de e-learning português". Instituto Politécnico de Lisboa: http://repositorio.ipl.pt/handle/10400.21/2323

Lisbôa, E. S., J. B. B. Junior, et al. (2009). "O contributo do vídeo na educação online." Actas do X Congresso Internacional Galego- Português de Psicopedagogia: 5858-5868.

Macy, M. (2011). Technology use as transformative pedagogy: Using video editing technology to learn about teaching. ProQuest Dissertations \& Theses, University of South Florida. Ph.D.

Miranda, F. M. W. (2008). Audiovisual education : a study of video production as a pedagogical instrument in the teaching-learning process. UNICAMP: Programa de Pós-Graduação em Multimeios. Campinas, SP, Universidade Estadual de Campinas . Instituto de Artes

Ribeiro, R. (2011). EduCast@FCCN. FCCN. Jornadas FCCN 2011, FCCN.

Ribeiro, R. (2011). Video Production Studio and Banco de Video. TERENA. TERENA TF-Media, TERENA.

Rosaen, C., M. Lundeberg, et al. (2010). "The Case for Constructing Video Cases: Promoting Complex, Specific, Learner-Centered Analysis of Discussion." Educational Technology 50(1): 18-22.

Silva, A. F. M. d. (2010). 0 uso do vídeo no processo de ensino-aprendizagem : análise de vídeos em manuais escolares e percepções dos professores e alunos sobre as potencialidades pedagógicas do vídeo. BUM - Dissertações de Mestrado, Universidade do Minho. Master.

So, W. W.-m., J. W.-c. Pow, et al. (2009). "The interactive use of a video database in teacher education: Creating a knowledge base for teaching through a learning community." Computers \& Education 53(3): 775-786. 
Soares, C. (2011). Apresentação de candidatura ao Prémio Excelência E-learning. U.Porto. Portal de E-learning U.Porto, Portal de E-learning U.Porto.

Souza, K. I. d. (2009). Digital video education : narrative audiovisual application. Ciencias Sociais na Educação. Biblioteca Digital da UNICAMP, UNICAMP. PhD.

Vena, F. (2009). SWITCHcast - a new approach to video management systems. TERENA. 1st Media Management and Distribution Workshop, TERENA - TF-Media.

Wieling, M. B. and W. H. A. Hofman (2010). "The impact of online video lecture recordings and automated feedback on student performance." Computers \& Education 54(4): 992-998.

Zbinden, A. (2010). TF-Media introduction and SWITCHcast update TERENA. GRNET Academic Media Casting workshop \& TF-Media Task Force meeting, TERENA TF-Media. 